REAL TITLES AND FOOLISH ONES. To the Editor of THE LanceT.

Sin,-The London Medical Directory, I conceive, is likely to become a book of great utility, if not abused. It is therefore of importance that its purposes should be distinctly understood. The preliminary questions put to medical practitioners by the Editors, as to name, residence, \&c., are distinct enough ; but what are we to understand by a " learned society," or " a consulting practitioner,"-terms which occur in the inquiries? Does the former embrace purely medical societies, such as the Hunterian, the South-London, the Guy's Physical? Or are we to include under that term all literary and scientific institutions which relate to learning, such as the Southwark, or any learned society which can be entered mercly by virtue of a subscription? Is a membership of the Sydenham Society, also, expected to be enumerated? These associations have been catalogued among their titles by some, and not by others, which difference should, if possible, be avoided. Is the term "consulting practitioner" intended to be limited to purely consulting practitioners? I hope not, as very many general practitioners set apart certain hours during the day, for receiving professional visits at home. One more query: Are honours received during pupilage to be enumerated? One or two medical men, I perceive, have mentioned them.

I remain, Sir, your obedient servant,

T. H. D.

[None but medical and purely scientific societies ought to be named. Hours of consultation may be, properly enough, announced by any practitioner. "Honours" obtained during pupilage do not confer titles, and should not be paraded. True, the membership of some medical and scientific societies confers no public fame, or title, or dignity; yet, where the society is not purely local, an index to the London associates may prove useful in the Directory; but the crowding of too many feathers in the cap would become only an index to the vanity of the wearer. In fact, without reflection, a very silly exhibition may be made in the Directory, as well as a very useful one.-ED.]

\section{THE LOCAL TREATMENT OF NEURALGIA.}

\section{To the Editor of The Laxcet.}

Sir,-I presume the "tobacco controversy" to be now nearly at an end; and it was, I confess, with feelings of great pleasure that I read, in your last week's journal, a communication from a gentleman, who seems well and practically acquainted with the effects of this marcotic application, stating, that the infusion applied topically in cases of tic douloureux, is "completely unproductive of the slightest mitigation of pain," and the " extract is equally inert."

As we possess constitutional remedies of undoubted efficacy in neuralgic affections, I have never been, by the florid representation of a well-wrought case, betrayed into the expectation of reaping the slightest permanent benefit from the employment of any local agent whatever. It is a thing utterly inconsistent with our notions of true physiological principles, to magine that a disorder, claining for its origin a remote source of irritation, can, by an application to the seat of pain (which is the mere external manifestation of internal mischief) be followed by other than transient alleviation. Sir Astley Cooper predicted that the undiluted super-acetate of lead, pencilled over the affected part, would so deaden the morbid sensibility of the excited nerve, as to produce complete relief. The suggestion seemed plausible, and was acted upon; but, as he himself acknowledges, it was subsequently abandoned as useless. Veratria, in its day, was vaunted as a never-failing remedy, until morphia usurped its place, and was, in its turn, laid upon the shelf. Everybody remembers the eulogies bestowed upon the rirtues of strychnia, but what were they in comparison to those of belladonna, in the hands of other practitioners? A notable discovery was palmed upon the public, some ycars since, as a perfect panacëa, and when the denouement came, it was found to consist of the potassio-tartrate of antimony! Aconite is still before the world, and whether internally or externally used, or both, is declared to be the one thing needful; but even aconite appears to run some danger of being superseded by tobacco.

When we look at the enumeration of topical applications which have reigned in triumph, been denounced, and consigned to oblivion, we may well, I think, be pardoned for questioning their ntility. Tobacco is one of these exploded nostrums, which has been lately raked from its ashes, and re-applied in practice. There is no modern discovery here; what tobacco can effect in eighteen hundred and forty-five, was effected by cataplasms of the extract many years ago. In the list of " $\mathrm{Cn}$ - successful Modes of Treatment," which I made in 1840, and published the following year, this identical extract of tobacco ccupies a prominent place.

It is almost marvellous that practitioners, with such glaring testimony before their eyes, should still revert to the beaten track of their predecessors.

Let us, for the sake of exemplifying the fallacy of this loca treatment, take an example of facial tic, such as frequently presents itself to our notice, in which the ramifications of the fifth pair of nerves on the entire half of the face are affected with exquisite intermittent pain: the forehead, eye, teeth, tongue, and cheek are all involved. Would the judicious practitioner, without enquiring into the history of such a case as this, rest satisfied by devoting his whole attention to the external manifestation of mere symptoms? No. His first duty would be to search out diligently the complications of the malady: its connection with disordered visceral function, whether of the stomach, liver, bowels, or uterus, and to restore those functions to healthy action. This is the great secret of all successful treatment, and will do more for the credit of the practitioner than could be effected by all the preparations of belladonna, aconite, or tobacco, which the ingenuity of despair has ever invented.

We are really indebted to men who, like Mr. Blanch, contravene, by the direct evidence of facts, the value of those general principles which are sought to be established by a fer ambiguous and isolated cases. I have not the slightest dou't, from the effects I have repeatedly witnessed of the topical applications above enumerated, that his observations, and the conclusions at which he has arrived, are substantially and entirely correct. I am, Sir, your most obedient servant,

R. H. ALLNATT, M.D.

\section{THE RECENT CASE OF PITYRLASIS NIGRA.} To the Editor of THE LANCET.

Sin,-I can assure you that it is with painful feelings of sorrow and regret, that $I$ feel myself obliged to trespass on the pages of your Journal, and the time of your numerons readers, to refute the unfounded and calumnious aspersions cast on my moral and professional character by Dr. Read, of Belfast, and published in the last number of the Dublin Medical Press.

The Doctor's anger appears to have been excited by a short and slightly incorrect report of a case of mine, which was read at the last meeting of the Medico-Chirurgical Society, and reported in The Lancet, as follows:-

"A case of pityriasis nigra, which"occurred in the practice of Mr. Teevan, was then read. The patient, a young lady from the neighbonrhood of Belfast, was otherwise healthy. The disease having baffled the skill of the Belfast physicians, the patient was brought to London, where her father consulted Dr. Chambers, and other medical men, and finally placed her under the care of Mr. Teevan, by whom, on more than one occasion, she was carefully watched, as he anticipated the case was one of imposture. Reiterated observation convinced him to the contrary. Her disease commenced with irritation of the brow and eyelids, which lasted for about ten minutes, and there then ensued an exudation of a black fluid, which gave the parts the appearance of being smeared with Indian ink. The secretion was removable by washing with a sponge and water, and was renewed in the course of eight hours; the disease finally disappeared; the treatment that was employed was merely palliative." "Such," observes Dr. Read, "is the narrative of Mr. Teevan; and it becomes my office to prove that it would be difficult to find a parallel instance of inaccuracy, misrepresentation, and false and ungrounded conclusions, introduced to the notice of any Society, learned or wnlearned. My proofs will be principally copied from the authentic letters of the young lady's father, now lying before me; as well as by criticism on his statement, with his own words and treatment of the case."

Now, as the greater portion of the Doctor's letter consists of the private letters of the young lady's father, which were written to him in confidence, and, singularly enough, published without the knowledge or consent of the writer, it is not my intention to follow the Doctor's unprofessional example in re-publishing them; and the more so, as they are as unnecessary for my defence, as they were to establish his groundless accusations. I shall now disprove the unfounded assumptions and erroneous conclusions of the Doctor, in the order in which they are stated:-

1st. A young lady from the neighbourhood of Belfast.

Dr. Read says, "Mr. Teevan must know that her abode is not very far beyond the city of Londonderry; but for his future inormation I will inform him, what it is highly probable he does not know, that the place is more than seventy Irish miles (between ninety 